\title{
Avaliação da eficácia dos extratos de Malva sylvestris, Calêndula officinalis, Plantago major e Curcuma zedoarea no controle do crescimento das bactérias da placa dentária. Estudo "in vitro".
}

\author{
Marilene da Cruz Magalhães Buffon'; Maria Lúcia da Costa Lima²; \\ zabel Galarda33; Laura Cogo ${ }^{3}$
}

${ }^{1}$ Professora do Departamento de Saúde Comunitária da UFPR

${ }^{2}$ Professora do Departamento de Fitopatologia da UFPR

${ }^{3}$ Professora do Departamento de Patologia Básica da UFPR

\begin{abstract}
RESUMO
Este estudo teve como objetivo avaliar "in vitro" a eficácia dos extratos fluídos de quatro plantas: Malva sylvestris, Calêndula offic inalis, Plantago major e Curcuma zedoarea; No controle da placa bacteriana e comparadas com a solução de Digluconato de Clorhexidina a $20 \%$. Os extratos fluidos de Calêndula officinalis e Curcuma zedoarea apresentaram em média os melhores resultados.

Palavras-chaves: fitoterapia, prevenção, placa bacteriana.

ABSTRACT

This papera imed at assessing how successful fluid extracts from : Malva sylvestris, Calêndula offic inalis, Plantago major e Curcuma zedoarea could be in tube, so as to control bacterial plaque and also compared to Clorhexidina Digluconato solution at $20 \%$. Fluid extracted from Calêndula officinalis and Curcuma zedoarea were the ones chich presented better results, roughly spesking.

Key words: phytotherapy, pervention,bacterial plaque.
\end{abstract}

\section{INTRODUÇÃO}

A arte dos benzedores, curandeiros e xamãs, herdados dos magos e feiticeiros de outrora, pode servista hoje, em teste, nos laboratónios científic os, os quaispassaram a avaliar experimentalmente a veracidade destas informações, tendo em vista a descoberta de novos medicamentos, com base justamente nos conhecimentos que foram adquiridos durante milhares de anos e repassa dos de geração em geração por aqueles que são os ancestrais da ciência modema.

Asinformações sobre os usos das plantasmedic ina is e suas virtudesterapêuticas foram sendo acumuladas durante séculos, e muito desse conhecimento empínico se encontra disponível atualmente. De domínio público, o conhecimento sobre as plantas medic inais representou e ainda representa o único recurso terapêutico de muitascomunidadese grupos étnic os. Essa prática, que se caracteriza pela utilização dos recursos naturais como forma de tratamento e cura de doenças, é tão antiga quanto a espécie humana. Aldous Huxley, famoso por suas obras de fic ção científica, a misca-se a dizer que "o homem deve ter sido antes farmacologista que fazendeiro" (Lobo, 1996), aludindo à grande importância e preocupação da espécie humana com a manutenção de sua integridade física desde os primórdios da civilização.

Nesse contexto, um dos assuntos mais integrantes e fascinantes da pesquisa com plantas medic ina is reside na origem desse conhecimento, na forma e nos procedimentos que o homem utilizou para descobrir as virtudes terapêuticas das espécies vegetais. Sem dúvida, a origem dessas desc obertas se encontra na observação constante e sistemática dosfenômenos e características da natureza e na conseqüente experimentação empírica 
desses recursos. O homem deve ter avaliado por si mesmo várias espécies, que de a lguma foma sugeniram a potencialidade de uso para amenizarseusproblemas, seja como medicamento, seja como alimento ou produção de femamentas e artesanatos; Santos, 1988.

Com certeza, inúmerasespéc ies vegetais foram incorporadasà medic ina tradicional, únic a e exc lusivamente, pelo acaso, caracterizado pelo uso empíico de espécies vegetais, seguido de a valiação, mesmo que nústica e grosseira, dos sina is e sintomas que a pareceriam após seu consumo, até selecionar pela qualidade de respostas, se determinada espécie Ihe seria útil ou não. O método usado é o mesmo método da tentativa e erro, a inda muito comum e útil em pesquisas de diversas áreas do conhec imento científico, que serve para mostrara forte ligação entre o conhec imento populare o científico (Guyot, 1990).

Com base no uso e conhecimento popular, o importante crescimento mundial da fitoterapia dentro de programas preventivos e curativos (Guyot, 1990) tem estimulado a a valiação da ativida de de diferentes extratos de plantas para o controle da placa bacteriana (Osawa et al., 1990 l; Osawa et al., 1990 II). Diversos trabalhos tem demonstrado que a placa dental é o fator deteminante da cáne e doença periodontal, justificando desta maneira, a utilização de medidas para o seu controle (Axelsson \& Lindhe, 1974; Komman, 1986). Mesmo assim, os programas ofertadosa população carente dificilmente atingem os objetivos em sua plenitude, uma vezque desvinculam oscomponentessociaisna incidência da cárie e doença periodontal, em função de que a maiorparte da população brasileira não tem condições financeiras para aquisição periódica dos instrumentos para o controle bacteriano, quer sejam mecânic os ou químic os, fazendo com que o perfil epidemiológico brasileiro seja desastroso (Buischi et al, 1989; Medeiros, 1991). Desta maneira, com a placa bacteriana não sendo adequadamente controlada, instala-se um processo de contínua destruição, comprometendo o dente e o periodonto e contribuindo para diminuição da longevidade dos dentes (Glickman, 1974; Rateitschak et al., 1989). Este fato justifica a intensific ação das medidas de prevenção da cárie e da doença periodontal baseadasno controle da placa supragengival através de meios químicos e mecânicos (Suomi et al., 1971; Axelsson \& Lindhe, 1978; Lobene, 1979; De Micheli \& Sarian, 1990).

Face as considerações expostas, pretende-se investigar a eficácia dos extratos de Malva sylvestris, Calêndula officinalis, Plantago major e Curcuma zedoarea no controle do c rescimento das bac térias da placa dentária, comparando os extratos com a solução de Digluconato de Clorhexidina a $20 \%$, que é comprovadamente eficiente no controle da plac a bacteriana, atuando de forma bactericida e bacteriostática, porém deixando uma pigmentação amamonzada na língua, dentese restaurações, quando utilizado (De Micheli, 1990).

\section{MATERIAL E MÉTODOS}

A atividade da solução de Digluconato de Clorhexidina a $20 \%$ e dos extratos de Calêndula offic inalis, Malva sylvestris, Plantago majore Curcuma zedoarea foram testadas sobre o cultivo misto de bactérias coletadas da placa dental. Paralelamente foi feito teste com culturas puras - ATCC - (American Type Culture Collection) de algumas bactérias encontradas em placa dental: Streptococcus mutans, Streptococcus sa liva nius, enteroc occus faeca lis, Sta phylococcusepidemidis, Staphylococcus saprophytic us, Staphyloc oc cus aureos, Streptococcus pyogenes, pseudomonas aenuginosa, proteus mirabilis, bacillus subtilis e 
corynebacterium matruchotr.

Inic ialmente o material coletado da placa dental foi inoculado em meio de cultivo líquido de Tryptic Soy Broth (ISB) da Biobrás, para enriquecimento e incubado a $37^{\circ} \mathrm{C}$ durante 24 a 48 horas.

Dos tubos com crescimento, c uja turbidez foi acertada ao do tubo n. 5 da Escala de MacFarland ( equivalente a um milhão e quinhentos mil bactérias porml) foi retirado $0,1 \mathrm{ml}$ da cultura e semeado em placas de T.SA., com auxílio de alça de Drigalski. A seguir sobre a superfície semeada foram colocados discos de papel de filtro estéreis, impregnados com 0,05 ml dos extratos dasplantase da solução de Diglucona to de Clorhexidina a testar. É o método de Kirby Bauer basea do na difusão em gel da substância antibacteriana.

Após a incubação de 24 horas a $37^{\circ} \mathrm{C}$, observar-se o crescimento bacteriano ao redordos disc os ou a sua ausência em foma de halos. Os diâmetros dos halos de inibição foram medidos com auxilio de régua. Foi observado a inibição total ou parcial da microbiota cultivada.

Em todosos experimentos, como termo de comparação e como teste positivo, foram utilizado discos de papel impregnados em Clorhexidina.

Foram coletadas 37 amostras de placa bacteriana.

\section{Resultados e Disc ussão}

A população brasileira ao longo dos anos tem utilizado de diferentes formas extratos de plantas, para solucionar doenças da cavidade bucal e percebendo a importância no repasse desses conhecimentos, resolvemos testar "in vitro" os extratos de quatro plantas amplamente utilizadas pela população, e com isso contribuir com informações para indicação e controle do uso a dequado dessas espécies de plantas.

Adotou-se o método "in vitro" de venific ação de atividade antimic robiana pelo contato direto, através dos disc os de papel embebidos pelos extratos das seguintes plantas: Malva sylvestris, Calêndula officinalis, Plantago major e Curcuma zedoarea, contra os gemes (bac térias) contidos em placas de cultura. O método de contato direto pemite uma análise comparativa entre os extratose a solução de Digluconato de Clorhexidina a $20 \%$.

A seleção dos inóculos utilizados, no presente trabalho, baseou-se noslevantamentos da ecologia oral que apontam os estreptococos do grupo alfa - gama como os mais representativos da flora oral, juntamente com os estafilococos, difteróides. Asbactérias foram testa das em cultura spuras e a tra vés de culturas mistas, estas provenientes de placa dentária que foi obtida de um único paciente adulto.

Com as culturas mistas, pretendeu-se verific ar a ação dos extratos de plantas sobre bactérias de ocomência freqüente na placa dentánia.

Os extratos das plantas testadas possuem algumas propriedades fitoquímicas. $A$ Curcuma zedoarea possui óleos essenciais que carac terizam o aroma da planta e atuam como analgésic os, antiespamódicos, antivirótic os, cicatrizantes, desinfetantes, são auxiliares na recuperação do tecido da pele e apresentam ação anti-inflamatónia. O extrato da Plantago major, possui ação adstringente, cicatrizante, antimic robiana, anti-inflamatória, devido a presença do componente fitoquímico tanino (são bons inibidores enzimátic os e atuam como anti-envenenamento por detemina dosalca lóides) e mucilagens (suco visc oso que funciona como anti-inflamatório, cicatrizante e protetordas mucosas). A Malva sylvestris e a Calêndula officinalis a presentam também mucilagem, taninos, óleos essencia is e 
flava nóides (evitam que os homônios propiciadores do câncer se liguem às células nomais). Santos, 1988.

Os quatros extratos foram testadose comparados com a solução de Digluconato de Clorhexidina a $20 \%$ que serviu como controle positivo, pois já é amplamente conhecido o seu efeito bactericida e bacteriostático sobre as bactérias da placa dentánia.

Os resultados correspondem às médias dos 37 halos de inibição, expresso em milímetros, correspondente as 37 repetições de cada extrato da planta testada.

As leituras foram realizadas com uma lupa, para melhor análise do crescimento de colônias minúsculas que cresceram no interior dos halos de inibição e que logicamente resistiram às soluções testa das.

As bactérias que cresceram no interior dos halos de inibição foram as seguintes: Enterococcus faecalis, Enterobacter aerogenes, Serratia liquefaciens, Proteus mirabilis, Staphylococcus epidermidis. Essas bactérias são transitónias na cavidade bucal e não possuem papelsignificativo no processo da cárie dentária e da doença periodontal mesmo estando presente na placa dentária.

TABELA 1- Ação do extrato de Calêndula officinalis, Malva sylvestris, Plantago major, Curcuma zedoarea e Digluconato de Clorhexidina a $20 \%$, sobre as 37 amostras de bactérias da placa dentánia.

\begin{tabular}{l|c|c|c|c|c|c}
\hline \multirow{2}{*}{ EXTRATo } & \multicolumn{2}{c|}{ Inibição Total } & \multicolumn{2}{c|}{ Inibição Pa rcial } & \multicolumn{2}{c}{ Sem inibição } \\
\cline { 2 - 8 } & $\mathbf{N}^{\circ}$ a mostras & $\%$ & $\mathbf{N}^{\circ}$ a mostras & $\%$ & $\mathbf{N}^{\circ}$ a mostras & $\%$ \\
\hline Calêndula offic inalis & 6 & 16,4 & 17 & 45,9 & 14 & 37,8 \\
\hline Malva sylvestris & 6 & 16,4 & 16 & 43,2 & 15 & 40,5 \\
\hline Plantago major & 5 & 13,5 & 16 & 43,2 & 16 & 43,2 \\
\hline Curcuma zedoarea & 4 & 10,8 & 15 & 40,5 & 18 & 48,6 \\
\hline $\begin{array}{l}\text { Digluconato de } \\
\text { Clorhexidina }\end{array}$ & 37 & 100 & & & & \\
\hline
\end{tabular}

\section{GRÁPCO 1}

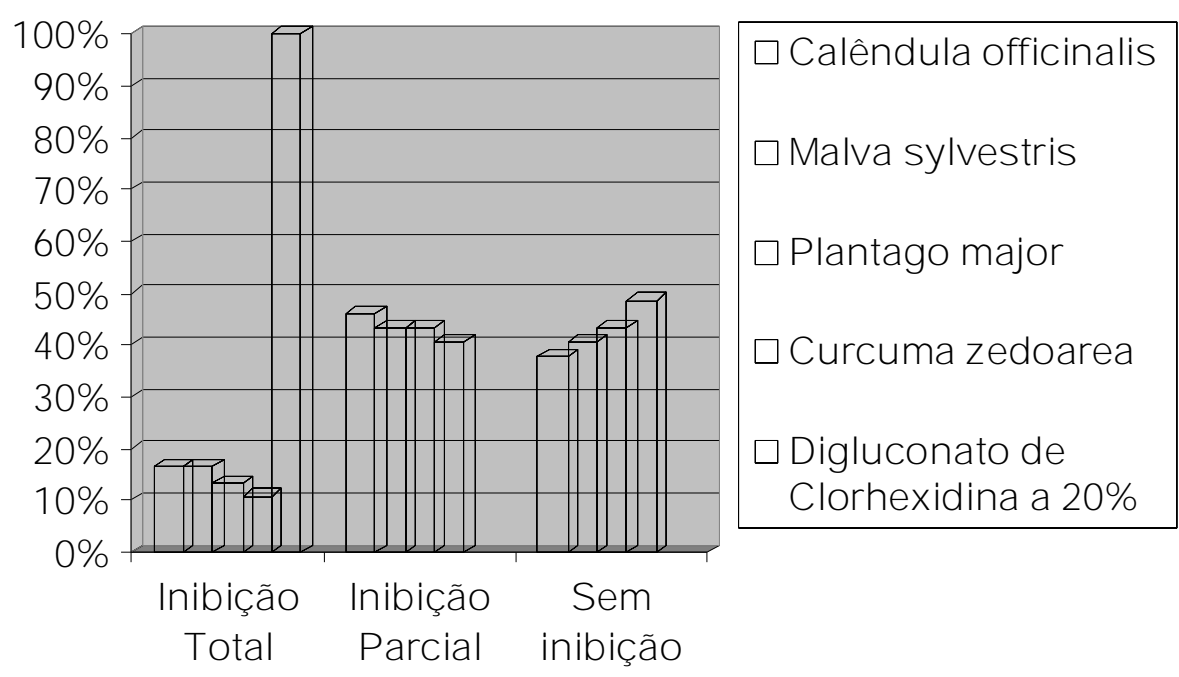


A tabela 1 mostra que o extrato de Calêndula offic inalise Malva sylvestrisapresentaram um índice de inibição total no crescimento das bactérias da placa dentária em tomo de $16,4 \%$. Os extratos de Plantago major e Curcuma zedoarea apresentaram um índice de inibição total em tomo de 13,5\% e 10,8\% respectivamente.

Em 17 amostras o extrato de Calêndula offic inalis, ou seja 45,9\%, a presentou halo de inibição parcial e em 37,8\% não apresentou inibição.

Observamos que em uma mesma amostra de placa dentária as repetições apresentaram resultados com comportamentos diferentes.

TABELA 2 - Comparações de halos de inibição total dos extratos de Calêndula offic inalis (C), Malva sylvestris (M), Plantago major (P), Curcuma zedoarea (Z) e Digluconato de Clorhexidina a $20 \%$ (CL), em milímetros.

\begin{tabular}{c|c|c|c|c|c|c|c|c}
\hline Extrato & $\mathbf{C}$ & $\mathbf{C L}$ & $\mathbf{M}$ & $\mathbf{C L}$ & $\mathbf{P}$ & $\mathbf{C L}$ & $\mathbf{Z}$ & $\mathbf{C L}$ \\
\hline $\mathrm{ml}$ & 8 & 17 & 12 & 30 & 10 & 17 & 10 & 17 \\
\hline $\mathrm{ml}$ & 18 & 30 & 10 & 17 & 12 & 25 & 14 & 16 \\
\hline $\mathrm{ml}$ & 8 & 17 & 11 & 25 & 10 & 15 & 20 & 25 \\
\hline $\mathrm{ml}$ & 15 & 25 & 12 & 35 & 12 & 21 & 9 & 20 \\
\hline $\mathrm{ml}$ & 15 & 35 & 10 & 15 & 10 & 21 & & \\
\hline $\mathrm{ml}$ & 10 & 20 & 15 & 21 & & & & \\
\hline Média & $\mathbf{1 2 , 3 3}$ & $\mathbf{2 4 , 0 0}$ & $\mathbf{1 1 , 6 7}$ & $\mathbf{2 3 , 8 3}$ & $\mathbf{1 0 , 8 0}$ & $\mathbf{1 9 , 8 0}$ & $\mathbf{1 3 , 2 5}$ & $\mathbf{1 9 , 5 0}$ \\
\hline
\end{tabular}

\section{GRÁFICO 2}

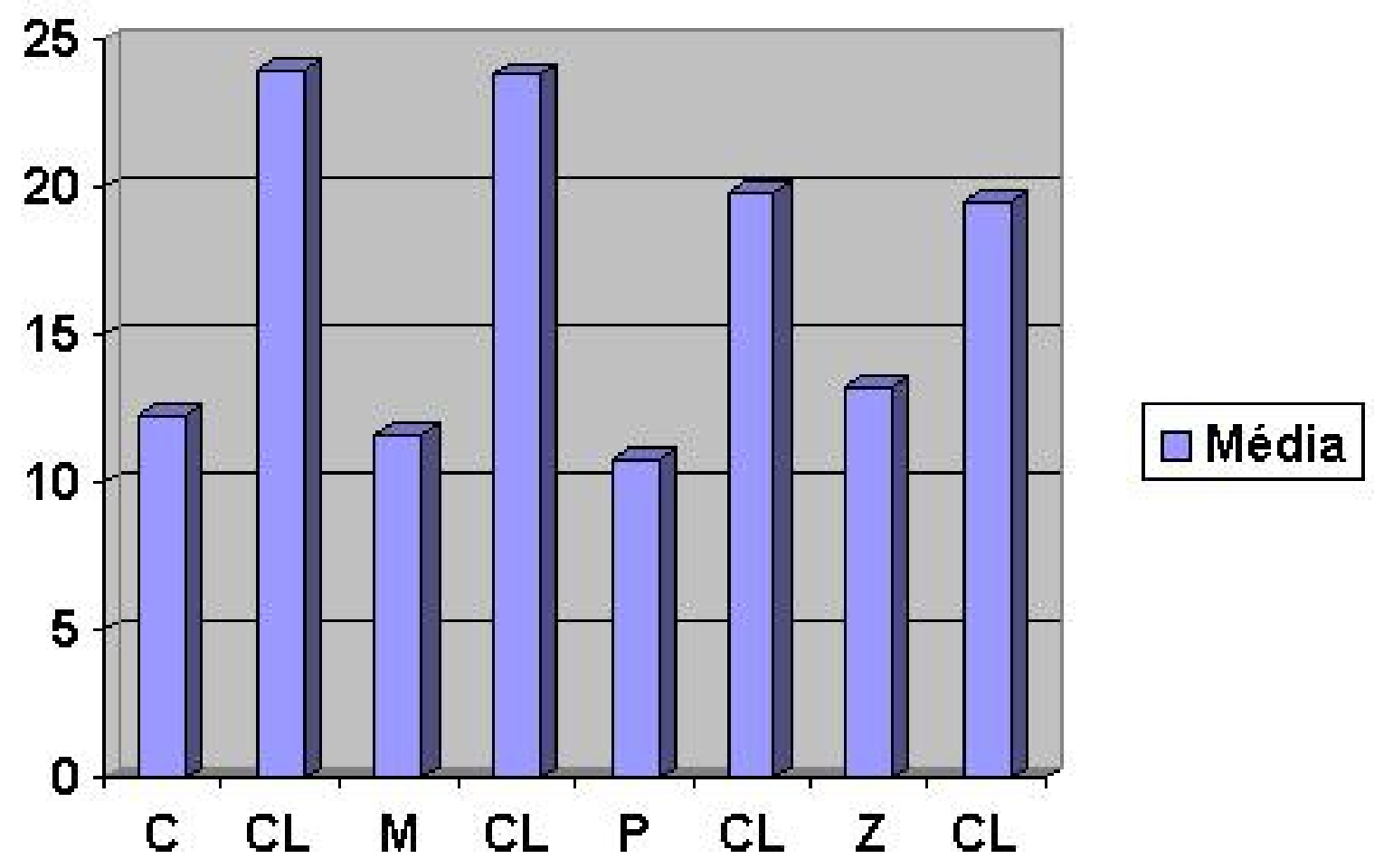


A tabela 2 evidencia que os extratos de Calêndula offic inalis e Curcuma zedoarea, apresentaram melhores médias em halos de inibição total em tomo de 12,33 $\mathrm{ml}$ e 13,25 $\mathrm{ml}$, respectivamente; porém sempre inferiores aos halos obtidos pela solução de Digluc onato de Clorhexid ina a $20 \%$. Estatistic amente a diferença entre os halos de inibição total entre os extratos não foram signific ativas.

\section{Conclusão}

A solução de Digluconato de Clorhexidina a $20 \%$ apresentou resultado $100 \%$ positivo como era esperado, inibindo o cresc imento das bactérias da placa.

Os extratos a presentaram um comportamento de inibição totale inibição parcial em tomo de $60 \%$ das repetições, mostrando portanto que apresentam propriedades de possível controle no crescimento das bactérias da placa dentánia.

As bactérias que cresceram no interior dos halos de inibição, foram isoladas e identific adas, sendo estas transitórias na cavidade bucal e não possuem papel significativo no processo da cárie dentária e da doença periodontal.

Há a inda muito a ser investigado, para melhor análise e compreensão dos fatores que influenciaram nos resultados.,

Sugerimosa condução de novos experimentos para comprovaros resulta dos obtidos neste estudo preliminar que indicam que os extratos testados apresentam resultados significativos, possibilitando mais um suplemento para o controle da placa dentária, podendo ser mais uma medida de prevenção e controle, contribuindo para qualidade da vida da população brasileira.

\section{REFERÊNCIAS}

1. AXELSSON, P\& UNDHE, J. Efficacy of mouthrinses in inhibiting dental plaque and gingivitis in man. J. Clin. Periodontol. , v. 14, no4, p. 205 - 212, 1887.

2. AXELSSON, $P \&$ UNDHE, J. The effect of a preventive programme on dental plaque, gingivitis and caries in school children. J. Clin. Periodontol. , v. 1, p.126 - 158, 1974.

3. BOWEN, WШAM H. Cariologia para a déca da de 90. Editora Santos, 1995.

4. BUISCHI, Y. etal. Salivary streptococcus mutansand cariesprevalence in brazilian sc hool children. Community Dent Oral Epidemial, v. 17, no1, p. 28 - 30, 1989.

5. CORREA J R, C.; MING, L C.; SCHEFFER, M. C. C ultivo de plantas medic ina is, condimentares e aromáticas. Curitiba : Emater - PR, 1991, p. 117.

6. DE MICHEU, G. \& SARIAN, R Placa bacteriana - Controle Químico. Revista da Associação Paulista de Cirurgiões Dentistas, V. 44, no6, p. 330 - 333, novembro - dezembro, 1990.

7. DUKE, J. A. Planta go major L - Pla ntain In : Handbook of medic inal herbs. Boca Ratton: CRC Press, 1986,p. 386.

8. FARMACOPÉIA DO ESTADOS UNIDOS DO BRASIL 2 ed. São Paulo. Gráfica Siqueira, 1959.

9. FONTQUER, Y. Plants medicinales: el dioscorides renovado. Barcelona: Labor 1985.

10. FRANCO, L L Plantas Medic inais. Editora Santa Mônica. v. 1, 1996, Curitiba - PR.

11. GJ ERMO, P. A clorhexidina na prátic a odontológica. Revista Gaúcha de Odontologia, v. 26, nô1, p. 22 - 26. J aneiro/Março, 1978.

12. GUCMAN, I. Priodontologia Clínica. 4 ed. México, Interamenicana, 1974.

13. GROSMAN, E. et al. Six-month study of effects of a clorhexidine mouthrinse on gingivitis in adults. J. Period. Research. Suplement, v.21, no16, p. 33 - 43, 1986.

14. GUYOT, M. M. Perspectivas de la fitoterapia. Acta Farmacêutica Bonaerense, v. 9, n.ㅇ 2, p. 131 - 138, 1990.

15. J ORGE, A. C. Microbiologia Bucal - Editora Santos, 2 ed., 1998.

16. KORMAN, $K$. The role of supragengivalplaque in the prevention and tratament of periodontal discase. J. Period. Res. Suplement 21 (16): 522, 1986. 
17. KRAMER, P. F. Promoção de Saúde Bucal em Odontopediatria. Editora Artes Médicas, 1997.

18. KRIGER, L Promoção de Saúde Bucal. Editora Artes Médicase ABOPREV, 1998.

19. LOBONE, R Effec ts of denifric ies on tooth Sta ins with contorlled brushing. J. A. D.A. 77: 849 - 855, 1968.

20. MEDEIROS, U. V. Aspectos gerais no controle da placa bacteriana. Controle de placa bacteriana em saúde pública. Revista da Associação Paulista de Cirurgiões Dentistas, v. 45, n.ㅇ 3, p. 479 - 483, 1991.

21. OSAWA, K et al. Studies of antibacterial activity of plant extractsand their constituentsagainstperiod ontopathic bacteria. Bull Tokyo Dent Call. V. 31, n 1, p. 17 - 21, 1990.

22. PENNA, M. Plantago major. In: Notas sobre plantas brasileiras. Rio de J aneiro: Araújo Penna Filho, 1921, p. $381-386$.

23. QUIGLEY, G. A. Conparative cleansing efficiency of manual and power brushing. J. A. D. A., v. 65 , p. 26 - 29, 1962.

24. RANAப, J . \& BIRAL, R Ava liação da atividade antimic robiana de soluções farmacêuticascomerc iais utilizadas como colutório. Estudo "in vitro". Revista Paulista de Odontologia, v. 11, n.o 1, p. 38 - 46,1989.

25. RATEITSCHAK, E. et al. Color atlas of dental medicine. v. 1 - Periodontology. Germany, Thieme Vemlac, 1989. 39p.

26. SANTOS, C.; TORRES, K; LEONART, R. Plantas medicinais (herbarium, flora et scientia). São Paulo. Icone / Scientia et Labor, 1988, p. 160.

27. SUOMI, J. D. et al. The effects of controlled oral hygiene procedures on progression of periodontic diseases in adults: results after third and final year. J. Periodontol. 42 (3): 151 - 160, 1971.

28. WTT, A. O uso de clomexidina em periodontia. Revista Gaúcha de Odontologia. V. 26, p. 16 - 19, janeiro/ março, 1978.

29. 正GAREШ, D. Mouthwashed in the tratament oral disease. Drugs 42 (1) : 171 - 173, 1991. 